\title{
The Characteristics Approach and its Application to Financial Liabilities, Financial Assets and Portfolio Choice
}

\author{
by Peter J. Franklin *
}

In the twenty or so years since Lancaster first introduced us formally to the idea of product characteristics, the characteristics approach has gained many admirers and followers. Katrak [4] has used the idea of product characteristics in international trade theory; Archibald and Rosenbluth [1] have re-worked Chamberlin's model of monopolistic competition using the characteristics approach; and Green included the characteristics approach in his masterly textbook on Consumer Theory [3].

Application of the characteristics approach to financial products, however, is relatively undeveloped. Rosa mentions the characteristics approach in his 1976 paper prepared for the Geneva Association [10]. A paper by Smith [12] is the only other reference which is directly in the Lancaster tradition.

This paper is an exploratory note. It represents an attempt to apply the characteristics approach to the demand for financial assets. As such it is essentially concerned with the problems of identifying and measuring the characteristics of life assurance products, and less concerned with the properties of investors' utility functions, though it is recognised that consideration of investors' utility is integral to a complete theory of demand for financial assets and portfolio choice ${ }^{1}$.

The paper is developed over five parts. In the first part the logic and advantages of the Lancaster approach over traditional demand theory are examined. In the second part we briefly review the main propositions and ideas of Lancaster. In part three the characteristics of certain life assurance products are identified, and from this analysis we examine some of the difficulties of applying Lancaster's theory to financial products. In the final two parts we attempt to extend our analysis to financial assets like equities and gilts, and examine the effects which the bundling of equities can have on the risk-return characteristics of asset portfolios.

* Lloyd's Research Fellow at the City University Business School, London. The author is especially indebted to Alan Munro for the hours of discussions spent over this and earlier papers. The continuing stimulus and support given over these months cannot be adequately compensated or recorded, but it is hoped that this footnote is some recompense. The author has also attempted to meet, wherever legitimate, the criticisms and suggestions of others.

1 See, for example, Green, [3], pp. 239-247. 


\section{Lancaster vs the traditional theory}

Traditional demand theory is now well-established. The basic approach is derived from Edgeworth, Slutsky and Hicks, and gives an analysis of consumer choice under a budget constraint. It is therefore possible to predict how a change in price or income will affect the consumer's demand for a given product; by the use of some simple geometry or algebra it is also possible to speak of the degree of substitutability or complementarity existing between any pair of goods.

As Lancaster points out, however, all this analysis has subsumed or "swallowed up " 2 the inherent physical properties of the goods themselves. He writes ${ }^{3}$,

"All economics textbooks use examples which draw upon common-sense knowledge of the relationship between properties of goods - that butter and margarine will be closer substitutes than butter and sugar, that the demand for gasoline will not depend much on the price of tea, and so on. But the actual demand theory set out in those books provides no warrant for statements of this kind and no necessary expectation that goods which are close substitutes in the eyes of one person will also be close substitutes to others."

Lancaster's analysis therefore " originated from the simple observation that demand theory was ignoring highly pertinent and obvious information, the properties of goods themselves" 4.

By adopting Lancaster's approach, demand theory is considerably strengthened. First, we can now legitimately talk about substitutes and complements by referring to the characteristics of any pair of goods. Secondly, as Lancaster's theory was designed to supplement rather than displace traditional demand analysis, many of the axioms and tools of existing demand theory are also adopted by Lancaster. Thus, indifference curves can be constructed between pairs of characteristics rather than pairs of goods, and the analysis of consumer's choice follows much the same pattern as before. A major difference, however, lies in the predictions of the model. Whereas traditional demand theory merely examines the substitutability of goods according to their status - normal, superior or inferior goods - by focussing on the characteristics of goods, it is possible to identify the status of any good's characteristics. Finally, the characteristics approach gives logic to product innovation, product differentiation and marketing - all matters which are uneasily dealt with in traditional demand theory.

\section{The characteristics approach reviewed}

As Lancaster admits, the characteristics approach to demand depends on two fundamental propositions : namely, (i) that all goods possess certain objective properties, and (ii) that these properties form the objects of choice by consumers.

2 Lancaster, [6], p. 4.

3 Ibid, p. 2.

4 Lancaster, [6], p. 2. 
As the properties of goods form the objects of choice, goods themselves do not directly provide utility. On the contrary, goods are chosen by consumers for the characteristics they possess, and it is the characteristics which directly provide utility.

Characteristics are therefore the objects of choice, and it is these which are ranked according to a consumer's preferences. But as all consumers are assumed to know the set of objective technical data which measure the relationship between a good and its characteristics, it follows that all consumers perceive a unit amount of a given product as possessing an invariable list of characteristics, with each characteristic measured according to technical objective information. The only room for judgement by the consumer, therefore, is in regard to his preferences about the characteristics, for the measure of any characteristic entering a good is invariable and known by all potential consumers.

In Lancaster's words then, demand for a good is a two-stage affair, for "it is composed of the relationship between things and their characteristics (objective and technical) and the relationship between characteristics and people (... involving individual preferences)." ([6], p. 7).

The relationship between goods and their characteristics is therefore an important part of Lancaster's theory, and in developing an understanding of this relationship Lancaster made use of a simple model showing the relationship between five foods and three nutrient characteristics possessed by unit amounts of each of those foods. Table 1 below reproduces a consumption technology matrix for the relationship between unit amounts of five foods and their characteristics. The table shows that a unit amount of milk (a half pint) possesses 160 calories, $9 \mathrm{mg}$ of protein, and 350 international units of vitamin A. Alternatively, if the characteristics of one egg were examined, the table shows that it possesses 80 calories, $6 \mathrm{mg}$ of protein, and 590 international units of vitamin $\mathbf{A}^{5}$.

Table 1

$A$ consumption technology matrix for foods and nutrients

\begin{tabular}{|c|c|c|c|c|c|}
\hline$\underbrace{\text { Foods }}_{\begin{array}{c}\text { Nutrient } \\
\text { Characteristics }\end{array}}$ & $\begin{array}{l}\text { Milk } \\
(1 / 2 \mathrm{pt})\end{array}$ & $\begin{array}{l}\text { Eggs } \\
(1)\end{array}$ & $\begin{array}{l}\text { Sirloin } \\
\text { Steak } \\
\left(\begin{array}{ll}3 & \text { oz }\end{array}\right)\end{array}$ & $\begin{array}{l}\text { Oranges } \\
\text { (1) }\end{array}$ & $\begin{array}{l}\text { Bread } \\
(1 \text { loaf })\end{array}$ \\
\hline Calories (no.) & 160 & 80 & 330 & 60 & 1225 \\
\hline Protein (mg) & 9 & 6 & 20 & 2 & 39 \\
\hline $\begin{array}{l}\text { Vitamin A } \\
\text { (international units) }\end{array}$ & 350 & 590 & 50 & 240 & 一 \\
\hline
\end{tabular}

Source : Lancaster, [6], p. 17.

5 It should be noted that Lancaster assumed the characteristics of goods to be linear and additive "to simplify the problem". ([5], p. 346). Accordingly, a doubling of the consumption of a unit amount of steak will double all the characteristics (linearity); by assuming additivity the amount of a characteristic possessed by any two goods (say steak and milk) is equal to the sum of the amounts of that characteristic possessed by steak and milk separately. Consumption of steak and milk would therefore provide the consumer with $20 \mathrm{mg}+9 \mathrm{mg}$ of protein. 
It is obvious, and admitted by Lancaster, that the number of characteristics of a good may amount to several dozen. In the examples noted above only three characteristics are noted, but many others exist. One of the major difficulties in making the theory operational then, is to identify and measure the relevant characteristics of a good. In some cases (goods) this may be relatively easy, but in others there may be considerable difficulties "partly because of the conceptual problems of identifying relevant characteristics and partly because the appropriate data have not hitherto been available". ([6], p. 113.)

However difficult it may be to identify and measure the relevant characteristics of a good, it should be emphasised that analysis concerned with the consumption technology matrix (with the relationship between goods and their characteristics) should be kept quite distinct from analysis of the relationship between characteristics and people. The ranking of one characteristic against another, or the ranking of different bundles of characteristics should be seen as clearly different from knowledge of the objective technical relationship between goods and their characteristics. Thus, although all consumers will be confronted with a consumption technology matrix such as shown above, whether eggs or milk are preferred will depend on an individual's ranking of utility from the consumption of calories versus vitamin $\mathbf{A}$.

\section{On application}

In making Lancaster's theory operational then, the major difficulty is in identifying and measuring the relevant characteristics. If we accept Lancaster's view that "it is essential that the characteristic be an objective universal property of the good (or activity) ", ([6], p. 114), then the intangible nature of many financial goods makes application of the characteristics approach that much harder. In addition, because many financial claims are either contingent on some uncertain events, or are claims which are irredeemable (and hence have an uncertain or variable capital value), this seems further to complicate the analysis.

Despite these difficulties it is useful to attempt to identify the characteristics of financial goods. As with other (non-financial) goods, the nature and weights of the technical characteristics entering financial goods can be used to explain the creation and demand for new financial instruments. Indeed, as with other goods, by identifying the characteristics of financial assets it is possible to explain how apparently quite different financial assets are in practice substituted for one another by investors (and creditors).

According to Lancaster we should " commence our search for characteristics of a good from the good itself... Every objective property of size, shape, performance is a potential characteristic. In principle, if we take an object, measure it in every possible dimension and in every aspect of performance, in every biological, chemical and physical aspect, we have evaluated all its possible characteristics". ([6], p. 114).

Not all these characteristics, however, will be relevant to consumers' choice. Thus, in Lancaster's words, the "fundamental operational problem is determining the relevant characteristics for choice". ([5], p. 115). This, in Lancaster's view, is determined in two stages. The first stage is to identify groups of similar goods; the second stage is to identify the relevant characteristics of each of the groups. 
Because we are dealing here with the application of the characteristics approach to financial assets, it may be thought that we can deal unerringly with the whole range of financial assets in one sweep. As Revell implies ([9], pp. 30-33), however, financial assets are heterogeneous, and the range of financial claims is immense. In addition, some are rather complex. In these initial paragraphs, therefore, our first stage must be to deal with a "group of goods of manageable size" and having, a posteriori, some similarity.

For this purpose, and without intention of prejudicing our results, we have chosen to examine the characteristics of life assurance policies, and following in the Lancaster tradition, define our characteristics for a "unit" of life assurance where this is measured by the sum assured.

Definition of the unit of life assurance is neither a simple nor obvious matter and therefore needs some justification. Rigorous interpretation of Lancaster's theory demands that analysis of the technical characteristics of products occur independently of the relative prices of goods (or their characteristics) and the budget of the consumer 6 . Hence, in measuring a unit of life assurance it is preferable to distinguish price (the premium or premium rate) from the technical characteristics of the product, and with this requirement the sum assured seems the best available measure of a unit of life assurance. This unit measure is also consistent with consumers' behaviour: withoutprofits mortgage endowment policies, for example, are effected for a given sum assured (usually identical to the amount borrowed from a building society), whilst the choice of policy is determined by the premiums charged by different insurers.

On the assumption that it is valid to measure a unit of life assurance by the sum assured, in Table 2 a simple consumption technology matrix for most, if not all types of life assurance product is defined. The list of relevant characteristics has been derived in the manner suggested by Lancaster - that is, by discarding all universal characteristics 7 , and by identifying and discarding all other characteristics which are technically or humanly irrelevant in affecting choice between life assurance products.

\section{Table 2}

A consumption technology matrix for life assurance products and their characteristics

\begin{tabular}{|l|c|}
\hline \multicolumn{1}{|c|}{ Life Assurance } & $\begin{array}{c}\text { Life Assurance } \\
\text { Characteristic Products }\end{array}$ \\
\hline 1. Term to maturity & \\
2. Premium payment, frequency and term & \\
3. Redeemability & \\
4. Claim payment frequency & \\
5. Risk of default & \\
\hline
\end{tabular}

Source: Franklin and Woodhead [2].

6 Even Lancaster confuses matters. In his analysis of the characteristics of American automobiles he considers price to be a valid product characteristic. See [6] p. 170. 
One of the surprising features of Table 2 is the small number of characteristics which can be used to differentiate life assurance products ${ }^{8}$. Thus, taking the characteristics in turn -

1. The term to maturity can be used to differentiate whole life policies from endowments and term assurances;

2. Premium payment frequency can be used to differentiate single premium policies from policies making annual, quarterly or monthly premium payments. Premium payment frequency is an important distinction between ordinary life assurance and industrial life assurance;

3. Redeemability can also be quantified : surrender values can be an important influence on consumer choice, and have frequently been used as a competitive weapon by life offices ;

4. Claim payment frequency varies with the type of life assurance product. Annuities may involve frequent (e.g. monthly) payment by the life office to the assured; payment on death or maturity of an endowment policy usually involves single payment only ;

5. The risk of default is the most difficult characteristic to quantify technically. In the mind of the consumer, however, it is probably associated with the firm's brand image, reputation and size.

These five characteristics usefully illustrate the main properties of life assurance products. It might be objected, however, that a major sixth characteristic has been overlooked - that is, a policy's share in the life fund's distributable profits. Inclusion of this "characteristic", however, is not easy. If a policy has a right to a share in distributable surplus, this is usually achieved by the life office giving reversionary or terminal bonuses which have the effect of increasing the value of the sum assured. The value of the sum assured though, has been chosen to act as the unit measure of a life assurance policy.

For this reason, because the technical characteristics of life assurance products are always related to the sum assured, it is legitimate to consider participation in profits as a pricing variable and not a technical characteristic. Thus given a sum assured, the effect of participation will be to affect the premium rate charged to the policyholder through time. Assuming profits to be made and distributed, a with-profits policyholder can be thought to get a given sum assured at an effective premium rate which diminishes as surpluses are declared. By comparison, a without-profits policyholder would pay the same premium constantly over the duration of the contract.

Surpluses, of course, are uncertain. Thus premium rates per $£ 1000$ sum assured on with-profits policies are also uncertain. Before purchasing his policy, the only information the policyholder can be supplied with will be the present (and continuing)

7 Lancaster, [6], p. 132 and p. 141.

8 This is only a short-list of characteristics. However, Lancaster noted his theory only had superiority over the classical theory of demand as long as the number of goods exceeded the number of characteristics. 
premium and the size of past bonuses - the latter giving him some indication of the possible size of the future "discount" or reduction in premium rate he may get by purchasing a with-profits policy.

Although the characteristics listed in Table 2 do indicate the group characteristics which affect the demand for life assurance products, and while the characteristics have been identified in the way suggested by Lancaster, the characteristics possessed by life assurance products do not behave in the way assumed in his simple theory - that is, the characteristics are neither linear, nor additive.

If the assumption of linearity held, using the life assurance example, a doubling of the sum assured (from $£ 1000$ to $£ 2000$ ) should also double the term to maturity, the premium payment frequency and, inter alia, redeemability. Even casual knowledge of the characteristics of life assurance products contradicts this: a doubling of the unit amount of life assurance has no necessary effect on the characteristics of life assurance.

Lancaster's assumption of additivity also appears not to hold. For example, if two life assurance products were purchased, one having ten years to maturity, and the second fifteen years to maturity, it could not be said that the term to maturity of the two policies was twenty-five years (i.e. the sum of the two policies).

The assumptions of linearity and additivity are not crucial to the validity of Lancaster's theory. That neither may be operational in practice, however, critically affects the application of the theory to the demand for financial assets, and as we shall see, also to financial portfolios and their selection.

\section{Choice under uncertainty}

The last two assertions can usefully be further explored if we attempt to extend Lancaster's theory to the demand for other types of financial asset. That is, as Lancaster's assumptions of linearity and additivity were used merely to simplify his analysis ${ }^{9}$, the validity of Lancaster's theory (at least in regard to financial instruments) relates to three issues: (i) whether there exists objective technical characteristics of financial goods; (ii) whether these characteristics are precisely measurable; (iii) whether characteristics are, in fact, the objects of choice by consumers.

The first issue has already been considered. Whilst we have attempted to identify the characteristics of life assurance products in the rigorous way outlined by Lancaster, it is worth recalling that Lancaster did not object to casual empiricism in this respect. In his 1966 paper, for example, he suggested that "simply asking consumers about the characteristics associated with various commodities..." 10 may be instructive : an

9 Lancaster, [5], p. 346.

10 See Lancaster, [5], p. 367. Adoption of this approach may enable other characteristics to be distinguished. One characteristic, which Carter believes the major characteristic, is

"the amount of protection as opposed to saving in the make up of the policy". If this "characteristic" cannot be adequately or legitimately dealt with in the list of characteristics already considered, then there may be more room for the pragmatic approach suggested by Lancaster and implied by Carter. 
investigation into policyholders' preferences for life assurance products would seem likely to confirm the list of (relevant) characteristics shown in Table 2.

The second issue, concerning the measurability of characteristics is much more intractable. Insofar as many financial instruments (including life assurance policies) are claims on the future - which, almost by definition must be unknown - then the characteristics of financial instruments - for example, their capital value - may not, in practice, be precisely or objectively measurable.

A good example, taken from the life assurance matrix, and to be examined again later, concerns the risk of default. Even for the most prosperous life office there is some, admittedly tiny, risk of failure. It would be misleading therefore to assume a zero risk of default on any policy. Yet, if this is the case, how is the risk to be measured: are we to assume probability values (and how are these to be obtained), or is some other measure of risk, such as Shackle's degree of potential surprise to be adopted?

The probability of default, of course, is not the only unknown. On a with-profits policy, for example, another unknown is the future effective premium rate. From casual conversation with brokers and others, the possibility of a fall in the premium rate (owing to increases in the sum assured through bonus issues) is an important feature of policyholder's choice. The possibility of a reduced premium rate, however, cannot be easily measured, nor indeed, can the actual size of the reduction be measured before it has taken place!

The role of time and uncertainty then, have important implications concerning the measurability of the characteristics of financial claims. Yet financial claims are not unique in this respect. Many other (tangible) goods have characteristics which are uncertain, or even affected by the degree of use. Furthermore, goods, other than financial goods, are often held as stores of wealth ; purchased and held for short time periods, and intended for later sale when income or other revenue depletes.

An example usefully illustrates some of these propositions. Assume a consumer wishing to purchase a consumer durable such as a washing machine. In regards to its performance (according to Lancaster, a legitimate characteristic to consider) an important characteristic will be its reliability - that is, its expected performance over time. Its expected performance, however, will not be certain. Although identical models will exist, and be tested, and a high degree of standardisation be commonplace, the performance of an individual washing machine will be uncertain, and in purchasing the good the consumer will have to rely on the average tested past performance of similar models as an indication of the expected performance of his own model.

The purchase of a complex long-lived commodity like a washing machine involves consideration of a future stream of characteristics. The stream is "uncertain" in three respects. Firstly, the time period over which the characteristics will be available will be uncertain; will the good last two, three or four years? Secondly, the characteristics are consumed over time; the availability and amount of the characteristics which flow from a good will be affected by the frequency and timing of consumption. Thirdly, the use of the good will involve consumption of the characteristics such that 
the "future store" of characteristics will deplete through time, and the good's properties therefore change noticeably 11 .

To suppose the existence of such uncertainties necessarily leads one to deduce the possibility that some characteristics may not be precisely measurable : the consumer will be faced with making a choice decision on information about characteristics which recognises uncertainty about the amounts of characteristics possessed by particular goods.

To suppose the existence of such uncertainties then, necessarily leads one to construct a modified theory of demand. That is, if the technical characteristics of goods are not precisely measurable - if some uncertainty about their quantity per unit of a good exists - then a theory of choice must make some statement about a consumer's uncertainty preference; that is, how he regards and measures this uncertainty.

As a first stage in developing such a theory of choice, it is possible to caricature the problem of uncertainty preference and uncertainty measurement. We can adopt, for example, ideas of risk aversion or risk loving consumers; we might also measure uncertainty mathematically, by using a subjective probability value, or in terms of our washing machine example, the variance of tested past performances.

Such measures, however, may be little more than a convenient fudge, and may conceal more than they reveal. The laboratory or testing conditions under which the performance of a washing machine is established, for instance, obscures the fact that the performance of an individual washing machine's performance will be affected by the user, his washing powder, the frequency and heaviness of his wash, the type of water supply, and the frequency of maintenance and care. The same washing machine may therefore provide very different levels of performance : the stream of characteristics expected to obtain over the (uncertain) life of the good will be affected by the degree of use, or, more generally, by the consumption activity itself.

Even where technical information about expected performance exists then, it is not a substitute for certainty about that characteristic. Choice (between complex goods like washing machines) is therefore made under conditions of partial ignorance where values for characteristics are approximate and not precise, and where uncertainty preferences may radically affect the choice decision.

But to suppose uncertainty, however, should not be a decision we take lightly, for it fundamentally affects the simplicity of the approach given by Lancaster. In brief, if we are unable to measure the characteristics of a good precisely, it affects our ability to define (with certainty) the characteristics frontier - the frontier showing combinations of characteristics which are technically most efficient. Secondly, because some goods (like financial goods) also have characteristics which are neither linear nor additive, the analysis of choice becomes complex. Thirdly, a more complicated utility function has to be assumed, where consumers also have regard to the uncertainty of the characteristics of a good. A revised theory of demand, therefore, is likely to be more complex than that outlined by Lancaster.

11 This analysis should not be seen as being intentionally analogous to A. Alchian's "Costs and Outputs" which first appeared in 1959. Some parallels can be drawn, however. 


\section{Bundling, portfolios and choice}

Already two approaches to the theory of choice under uncertainty exist. The first is the mean-variance approach which assumes (an investor's) choice to be determined by two criteria - the expected return on an asset (or portfolio) and its risk - and forms the dominant trend in financial theory ${ }^{12}$. The second approach is to use statepreference theory, where it is assumed "that the possibilities of consumption (or wealth) are conditional with respect to the fulfilment of numerous possibilities, which are mutually exclusive and which together exhaust the 'states of nature" "13.

Adoption of the mean-variance approach has implications concerning the characteristics which consumers (qua investors) consider relevant when choosing between financial assets and portfolios. Although life assurance companies and other investors probably seek to quantify four or five characteristics, such as marketability, term to maturity, redeemability, expected return and risk (measured by the variability of past returns), in simple versions of portfolio theory, choice between gilts and equities, and between equities is made on the basis of risk and expected return only. Assuming investors to be risk averse, it follows that for a given level of risk, investors will aim to maximise expected return, or for a defined expected rate of return, they will aim to minimise risk.

If investors behave in the way postulated by portfolio theory, then given values for expected return and risk of any two assets $A$ and $B$, where $A$ and $B$ are expected to earn 8 per cent per annum, but have differing degrees of risk, it follows that the asset with the least risk will be purchased. By purchasing both assets, however, it might be possible to reduce the level of risk below the risk associated with holding a single least-risky asset. That is, as the theory of portfolio selection relies on the proposition that the risk of an individual asset can be "diversified away" by purchasing other assets which have returns varying countercyclically, or more precisely, which have past rates of returns which are imperfectly correlated with one another, then the theory shows that the risk of a portfolio is not equal to the sum of the risks of the individual assets, but consists of a more complex relationship ${ }^{14}$.

The implication of this result for the application of Lancaster's theory to the demand for financial assets is that Lancaster's theory is entirely analogous with the theory of demand for financial assets which is found in the theories developed by Markowitz and Sharpe. A priori that is, consumers (qua investors) are not interested merely in the characteristics of individual financial assets. Investors, just like Lancaster's consumers, are interested in combinations or bundles of goods which provide greatest

12 See Green, [3], pp. 242 ff.

13 Rosa, [10], p. 40.

14 Discussion of the relationship can be found in J.H. Lorie and Mary T. Hamilton, The Stock Exchange, (Richard Irwin, Homewood Illinois, 1973), Chap. 10. The equation for portfolio risk is shown below, where $X_{A}$ and $X_{B}$ are proportions of the assets $A$ and $B$ entering the portfolio. $\sigma_{A}^{2}$ and $\sigma_{B}^{2}$ represent the variance of the past returns of $A$ and $B$, and $p_{A B}$ represents the correlation coefficient between assets $A$ and $B$.

$$
\sigma_{p}^{2}=X_{A}^{2}\left(\sigma_{A}^{2}\right)+X_{B}^{2}\left(\sigma_{B}^{2}\right)+2 X_{A} X_{B} p_{A B} \sigma_{A} \sigma_{B}
$$


utility. According to portfolio theory this is achieved if investors choose assets having imperfectly correlated returns - where the risks (or variances) of the assets are not simply added together. Such a result is shared by Lancaster's approach. As we have noted, he acknowledges the possibility that characteristics of goods may not be additive. $\mathrm{He}$ realises that when goods are consumed together, the total "portfolio" of characteristics of all the goods may often not be equal to the sum of the characteristics if each of the goods were consumed separately $\mathbf{1 5}$.

The application of the characteristics approach to the demand for financial assets therefore does appear to be fully compatible with the ideas developed by Markowitz et al. By dropping the assumption of additivity (and linearity), and by assuming investors to be interested in only two moments of the measurable probability distribution of returns, asset choice under uncertainty becomes a problem which is soluble. More importantly, as Lancaster implied, it also becomes possible to give logic to the creation of diversified portfolios "where goods in combination may possess characteristics different from those pertaining to the goods separately". ([5], p. 343).

\section{REFERENCES}

1. ARCHIBALD \& ROSENBLUTH : "The new theory of demand and monopolistic competition", Quarterly Journal of Economics, December 1975.

2. FRANKLIN \& WOODHEAD : The U.K. Life Assurance Industry - A Study in Applied Economics, Croom Helm, London, forthcoming.

3. GREEN, H. G. J. : Consumer Theory, Macmillan, London, 1976.

4. KATRAK, H. : "Human skills, R. and D. and scale economies in the exports of the United Kingdom and the United States ", Oxford Economic Papers, November 1973.

5. LANCASTER, K.: "A new approach to consumer theory", Journal of Political Economy, April 1966 ; reprinted in Ehrenberg \& Pyatt, Consumer Behaviour, Penguin, Harmondsworth, 1971.

6. LANCASTER, K. : Consumer Demand: A New Approach, Columbia University Press, New York, 1971.

7. MARKOWITZ, H. : Portfolio Selection: Efficient Diversification of Investments, John Wiley, New York, 1959.

8. MOORE, B. J. : An Introduction to the Theory of Finance, The Free Press, New York, 1968.

9. REVELL, J. : The British Financial System, Macmillan, London, 1973.

10. ROSA, J. J.: “La demande d'assurance non-vie : l'état actuel de la théorie", Geneva Papers on Risk and Insurance, No. 5, February 1977, 35-42.

11. SHARPE, W.F. : "A simplified model for portfolio analysis", Management Science, January 1963.

12. SMITH, K.V.: "The major asset mix problem of the individual investor", Journal of Contemporary Business, Winter 1974.

15 Lancaster [5], p. 343. 